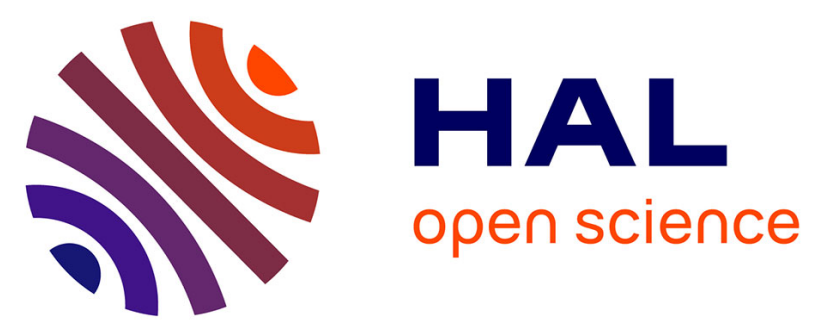

\title{
Beta energy dependence of the Ag-doped phosphate glass detector response
}

\author{
Y.O. Salem, A. Nourreddine, Z. El Bitar, N. Arbor, O. Bolusset
}

\section{To cite this version:}

Y.O. Salem, A. Nourreddine, Z. El Bitar, N. Arbor, O. Bolusset. Beta energy dependence of the Ag-doped phosphate glass detector response. Radiat.Meas., 2019, 126, pp.106136. 10.1016/j.radmeas.2019.106136 . hal-02264956

\section{HAL Id: hal-02264956 \\ https://hal.science/hal-02264956}

Submitted on 25 Oct 2021

HAL is a multi-disciplinary open access archive for the deposit and dissemination of scientific research documents, whether they are published or not. The documents may come from teaching and research institutions in France or abroad, or from public or private research centers.
L'archive ouverte pluridisciplinaire HAL, est destinée au dépôt et à la diffusion de documents scientifiques de niveau recherche, publiés ou non, émanant des établissements d'enseignement et de recherche français ou étrangers, des laboratoires publics ou privés.

\section{다)(1) $(5$}

Distributed under a Creative Commons Attribution - NonCommerciall 4.0 International 


\title{
Beta energy dependence of the Ag-doped phosphate glass detector response
}

\author{
Y.O. Salem ${ }^{a, b, *}$, A. Nourreddine ${ }^{a}$, Z. El Bitar ${ }^{a, c}$, N. Arbor $^{a}$, O. Bolusset $^{a}$ \\ ${ }^{a}$ Université de Strasbourg, CNRS, IPHC UMR 7178, F-67037 Strasbourg Cedex 2, France \\ ${ }^{b}$ Département de physique, Université des Sciences, des Techniques et Technologies, BP E3206, Bamako, Mali \\ ${ }^{c}$ Laboratory of Physics and Modeling, EDST, Lebanese University, 1300 Tripoli, Lebanon
}

\begin{abstract}
The radiophotoluminescent (RPL) signal of Ag-doped phosphate glass detectors to $\beta$ radiation is significantly influenced by $\beta$-particle energy. We investigate the $\beta$-particle energy and angular dependence of incident $\beta$ radiation on the RPL signal emitted from the detectors. The results of measurements and MCNPX simulations show that the detector sensitivity decreases with increasing $\beta$-energy and has little dependence on the angle of incidence. The consequence is that a dose assessment will be strongly biased if the detector calibration is performed with $\beta$-rays different from those monitored.
\end{abstract}

Keywords: Ag-doped phosphate glass ; Radiophotoluminescence ; beta dosimetry ; MCNPX

\section{Introduction}

RPL dosimeters are extensively used for monitoring the external dose of $\gamma, \mathrm{X}$ and $\beta$ radiations. After exposure to ionizing radiation the Ag-doped phosphate glass emits a fluorescence when excited with ultraviolet light (Miyamoto et al., 2010) with an intensity proportional to the amount of radiation received. RPL dosimeters are usually calibrated by a single reference energy before their use. The dose deposition from $\beta$ radiation in body tissue is highly non-uniform (Pinto et al., 2008), so due to its short range in matter, it causes more damage to workers' extremities. Thus accurate assessment of such dose becomes important (Durhan et al., 2002). Ideally it thus would be important to measure a $\beta$ dose with a detector

\footnotetext{
* Corresponding author. Tel.: +33 388106524 ; fax: +33 388106508 .

E-mail address: youbba-ould.salem@iphc.cnrs.fr
} 
whose response is independent of the energy. Contento et al. (1984) suggest in this case doing a calibration with a $\beta$ field of the same characteristics as measured in the monitored area.

In practice a major problem with RPL detectors for $\beta$ dosimetry is their effective limited thickness $(1.5 \mathrm{~mm})$. It results that the total energy deposit in the detector for the reference beta fields specified by the International Organization for Standardization ISO 6980-1 and the International Electrotechnical Commission IEC 62387 for dosimeter calibrations is not obtained for all these radiation fields. In many cases, the RPL response is not the same for the same absorbed dose of $\beta$ particles at different energies. For convenience, $\beta$ dosimeter calibrations are often done with $\beta$ rays emitted from ${ }^{90} \mathrm{Sr} /{ }^{90} \mathrm{Y}$, and the result is used to evaluate the dose from to other $\beta$ sources. We investigate the $\beta$ energy dependence of the emitted RPL in Ag-doped phosphate glass detectors in order to estimate the skewing of a dose result. The errors on the calibration according the angle of incidence on the detector were also simulated with the MCNPX code for the beta fields provided by ISO 6980-1.

\section{Materials and methods}

\subsection{Description of the RPL dosimeter}

The RPL dosimeter consists of a plastic holder equipped with a flat Ag-doped phosphate glass detector $\left(35 \times 7 \times 1.5 \mathrm{~mm}^{3}\right)$ associated with filters of aluminum, copper, tin and plastic that aid discriminating among the radiations (Hocine et al., 2011). Information on the filter thicknesses has been described in detail by Huang and Hsu (2011). A glass contains by weight: $48.33 \% \mathrm{O}, 13.24 \% \mathrm{Na}, 6.18 \% \mathrm{Al}, 31.53 \% \mathrm{P}$ and $0.72 \% \mathrm{Ag}$ with a $2.6 \mathrm{~g} / \mathrm{cm}^{3}$ density (Salem et al., 2015). During an irradiation, luminescence centers in the glass are activated. Before reading a detector, the centers must undergo a stabilizing heat treatment ("preheating") at $100^{\circ} \mathrm{C}$ for $1 \mathrm{~h}$ to accelerate the build-up of colour centers (Jahn and Schumann, 1980). When illuminated under the UV laser beam of the FGD-660 readout module from Chiyoda Technol Corporation, the deexcitation of the centers is accompanied by an orange luminescence with an intensity proportional to the number of trapped electrons and thus proportional to the deposited energy dose. RPL centers do not disappear after a readout operation (Miymoto et al., 2010) which allows rereading a detector. Upon heating to $400^{\circ} \mathrm{C}$ for $1 \mathrm{~h}$, a detector is erased and can be reused. The highly sensitive reading technique of the 
reader based on pulsed UV laser excitation enables measuring $\gamma, X$ and $\beta$ radiation from a few $\mu \mathrm{Gy}$ to high levels of about $10 \mathrm{~Gy}$.

\subsection{Experimental aspects}

$\beta$ RPL dosimeter calibrations are usually done with beta rays from ${ }^{90} \mathrm{Sr} /{ }^{90} \mathrm{Y}$. Figure 1 shows the absorbed dose-response for ${ }^{90} \mathrm{Sr} /{ }^{90} \mathrm{Y}$ of a bare RPL detector and with $\beta$ ray filters of 0.2 and $0.5 \mathrm{~mm}$ of Plexiglass (Juto, 2002). It was obtained by irradiating the detector placed in the plastic badge equipped with the two filters (Hocine et al, 2011) on a $30 \times 30 \times 15 \mathrm{~cm}^{3}$ ISO water-filled phantom with a ${ }^{90} \mathrm{Sr} /{ }^{90} \mathrm{Y}$ irradiator of activity $33 \mathrm{MBq}$ at a distance of $30 \mathrm{~cm}$. The figure presents a linear response for normal incidence with and without filters of 0.2 and $0.5 \mathrm{~mm}$ Plexiglass with slight deviation around $10 \mathrm{mSv}$ for the $0.5 \mathrm{~mm}$ filter. An accurate dose assessment would be biased if we use the same RPL response to evaluate the dose from another $\beta$ emitter with an energy different than that from the ${ }^{90} \mathrm{Sr} /{ }^{90} \mathrm{Y}$ source. Hence the challenge is to find a real dose independently of $\beta$ energy. Angular dependence to $\beta$ rays from ${ }^{90} \mathrm{Sr} /{ }^{90} \mathrm{Y}$ taking into account the filter thicknesses was studied by Maki et al. (2015). It was observed that the RPL response decreases faster with angle when filter thickness increases.

To investigate the beta energy dependence of the emitted radiophotoluminescence in RPL detectors, we used our laboratory standard source of ${ }^{14} \mathrm{C}$ (maximum energy $0.156 \mathrm{MeV}$ ) and ${ }^{90} \mathrm{Sr} /{ }^{90} \mathrm{Y}$ (maximum energy $2.274 \mathrm{MeV}$ ). The $5 \mathrm{~cm}$ diameter sources have activities of 4720 $\mathrm{Bq}(07 / 12 / 2002)$ and $4370 \mathrm{~Bq}(30 / 04 / 2008)$, respectively. The bare RPL detectors were irradiated in the absorbed dose range of 0.02-1 mGy in contact with the source. For each dose level, five detectors were utilized. Dose deposition of beta energy within the RPL glass was calculated using the MCNPX code (Pelowitz et al., 2011).

\subsection{Simulations}

The RPL detector was simulated using MCNPX (Pelowitz et al., 2011) for the experimental irradiation conditions employed for the standard sources of ${ }^{14} \mathrm{C}$ and ${ }^{90} \mathrm{Sr} /{ }^{90} \mathrm{Y}$ described in section 2.2 and for the reference $\beta$ fields specified by ISO 6980-1 and IEC 62387 as well as for the beta rays emitted from ${ }^{40} \mathrm{~K}$ at different distances. For angular responses of the detectors, the simulations were performed for a $5 \mathrm{~cm}$ diameter, $0.25 \mathrm{~mm}$ thick $\beta$-particle source anodized on an aluminum substrate. The energy spectra used in the simulations were 
provided by the report of Stabin et al. (2002) and the ICRU report 72 (2004). The tallies $f 4$ and $f 6$ were used to determine the fluence and dose deposition of the beta particles within the detector. The difference from ${ }^{90} \mathrm{Sr} /{ }^{90} \mathrm{Y}$ on the calculated $\beta$ fluence per dose was compared with the experimental RPL signal per $\beta$ disintegration. Also, for each source, the response at incident angles of $0^{\circ}, 15^{\circ}, 30^{\circ}, 45^{\circ}$ and $60^{\circ}$ were computed with a stochastic uncertainty lower than $1 \%$. All simulated angular responses are evaluated per emitted $\beta$ received by the detector.

\section{Results and discussion}

\subsection{RPL energy dependence}

Figure 2 shows the experimental detector response per unit dose within the RPL glass as a function of maximum beta ray energy. Each energy point was obtained from the slope of the linear dose-response curve in the dose range of 0.02-1 mGy. The two points at 1.47 and 1.84 $\mathrm{MeV}$ were obtained using the MCNPX code by degrading the ${ }^{90} \mathrm{Sr} /{ }^{90} \mathrm{Y}$ source spectrum respectively through Plexiglass screens of 4 and $2 \mathrm{~mm}$. It can be seen that the response of the RPL detector decreases when the $\beta$ energy increases. A significant difference between beta rays from ${ }^{90} \mathrm{Sr} /{ }^{90} \mathrm{Y}$ and ${ }^{14} \mathrm{C}$ is observed. With a detector thickness of $1.5 \mathrm{~mm}$, the $\beta$ energy deposit is not total for all the radiation fields plotted. The maximum penetration depths of $\beta$ rays of different energies in the RPL glass are listed in the Table 1 (Berger et al., 2017). Depending on the $\beta$ energy, luminescence centers are created only in a surface layer of the exposed face of the RPL glass or over its entire depth. The ultraviolet laser beam of the reader which provokes emission of the RPL signal can reach only a depth of $500 \mu \mathrm{m}$ in the detector (Maki et al., 2015). Thus, some luminescent centers generated in the irradiation are not excited. It has been proposed that the energy dependence should be improved if the detector is thinned. Akselrod et al. (1996) propose to measure the beta dose using a very thin dosimeter.

\subsection{Difference from the measured RPL signal}

Figure 3 ( $a$ and $b$ ) shows the evolution of RPL signal per beta disintegration as a function of the absorbed dose for ${ }^{90} \mathrm{Sr} /{ }^{90} \mathrm{Y}$ and ${ }^{14} \mathrm{C}$ sources. In the dose range studied, the order of magnitude of these results for each beta source is almost the same. All responses in terms of 
RPL signal per beta disintegration tend towards an average value of $(1.29 \pm 0.06) \times 10^{-5}$ for ${ }^{90} \mathrm{Sr} /{ }^{90} \mathrm{Y}$ and $(2.22 \pm 0.09) \times 10^{-6}$ for ${ }^{14} \mathrm{C}$, with difference of $(82 \pm 6) \%$ for ${ }^{14} \mathrm{C}$ compared to ${ }^{90} \mathrm{Sr} /{ }^{90} \mathrm{Y}$.

The calculated difference from ${ }^{90} \mathrm{Sr} /{ }^{90} \mathrm{Y}$ compared to simulations and the experimental results is shown in Figure 4. MCNPX simulation results for all the reference $\beta$ fields were obtained by calculating the fluence per dose deposition of $\beta$ within the glass detector, because the RPL detector emitted radiophotoluminescent signal is proportional to the amount of radiation received. Good agreement is observed between the simulation results and the experimental results over the energy range studied. We can note that the difference with a $\beta$ emission from an unknown source can be high if calibration is done with ${ }^{90} \mathrm{Sr} /{ }^{90} \mathrm{Y}$ source. These significant differences must be taken into consideration to improve $\beta$ monitoring using RPL detectors. In their study on the development of thermoluninsecent $\beta$ dosimeters, Akselrod et al. (1996) indicate that the energy response may be considerably improved by using filters. A new RPL glass dosimeter badge designed to detect $\beta$-rays from ${ }^{147} \mathrm{Pm}$ (Maki et al., 2015) does not give an uncertainty on a dose assessment if the calibration is performed with beta rays other than the $\beta$ field of the monitored area.

\subsection{Simulated angular responses of $R P L$}

Directional differences from ${ }^{90} \mathrm{Sr} /{ }^{90} \mathrm{Y}$ were simulated at different distances as mentioned in ISO 6980-1. The simulation conditions can be seen in Table 2. For each angle of incidence, the RPL glass was computed on a $30 \mathrm{~cm}$ x $30 \mathrm{~cm}$ x $15 \mathrm{~cm}$ ISO water-filled phantom. Figure 5 shows that the detector response is almost the same relative to ${ }^{90} \mathrm{Sr} /{ }^{90} \mathrm{Y}$ regardless of the angle of incidence, which again shows that the measured response of the RPL material presents a strong $\beta$ energy dependence. For ${ }^{14} \mathrm{C}$, the available calibration distances vary from 0.006 to 5 $\mathrm{cm}$ (ISO 6980-1). This is less than half of the ISO phantom width. For this reason, we limit the angular simulation to a normal incidence at $5 \mathrm{~cm}$. The difference from ${ }^{90} \mathrm{Sr} /{ }^{90} \mathrm{Y}$ simulated at $30 \mathrm{~cm}$ on the phantom is $75 \%$. This difference was $74 \%$ in Figure 4 for both standard sources simulated in the experimental irradiation conditions described in section 2.2, i.e., RPL detector placed on the surface of the laboratory standard sources.

\section{Conclusion}


Silver doped phosphate glass detectors were investigated for beta radiation using the RPL technique. The results clearly indicate that RPL material presents a high beta energy dependence that should be taken into consideration for beta monitoring dosimetry. It was observed that a dose assessment will be strongly biased if the detector calibration is performed with a $\beta$-rays different from those monitored. A difference from ${ }^{90} \mathrm{Sr} /{ }^{90} \mathrm{Y}$ on the RPL signal emitted from the detector can reach more than $70 \%$ compared to beta radiations regardless of angle of incidence of lower energy.

\section{Acknowledgments}

The authors would like to thank Arthur Pape for pertinent comments on the manuscript; the staff of RAMSES Group of the IPHC, in particular Addil Sellam, Séverine Chefson and Nicolas Spanier, members of dosimetry service. 


\section{References}

Akselrod, M.S., McKeever, S.W.S., Moscovitch, M., Emfietzoglou, D., Durham, J.S., Soares, C.G., 1996. A thin-layer $\mathrm{Al}_{2} \mathrm{O}_{3}$ :C beta TL detector. Radiat. Prot. Dosimetry 66, 105-110.

Berger, M.J., Coursey, J.S., Zucker, M.A., Chang, J., 2017 (last update). NIST ESTAR : Stopping Power and Range Tables for Electrons.

https://physics.nist.gov/PhysRefData/Star/Text/ESTAR.html

Contento, G., Malisan, M R., Padovani, R., 1984. Response of thermoluminescence dosemeters to beta radiation and skin dose assessment. Phys. Med. Biol. 29, 661-678.

Durham, J.S., Zhang, X., Payne, F., Akselrod, M.S., 2002. Design of a finger ring extremity dosemeter based on OSL readout of alpha-Al2O3:C. Radiat. Prot. Dosimetry 101, 65-68.

Huang, D.Y.C., Hsu, S-M., 2011. Radio-Photoluminescence Glass Dosimeter (RPLGD). Advances in Cancer Therapy, Prof. Hala Gali-Muhtasib (Ed.), ISBN: 978-953-307-703-1, InTech, Available from: http://www.intechopen.com/books/advances-in-cancer-therapy/radio-photoluminescenceglass-dosimeterrplgd

Hocine, N., Donadille, L., Huet, C., Itié, C., Clairand, I., 2011. Personal monitor glass badge : theoretical dosemeter response calculated with the Monte Carlo transport code MCNPX. Radiat. Prot. Dosimetry 144, 231-233.

International Commission on Radiation Units and Measurements, 2004. Dosimetry of beta rays and low-energy photons for brachytherapy with sealed sources, ICRU Report 72.

International Electrotechnical Commission, 2012. Radiation protection instrumentation Passive integrating dosimetry systems for personal and environmental monitoring of photon and beta radiation, IEC 62387.

International Standardization Organization, 2006. Nuclear energy - Reference beta-particle radiation - Part 1: Methods of production, ISO 6980-1. 
Jahn, W., Schumann, W., 1980. Glass for radiophotoluminescence dosimetry. U.S. Patent $n^{\circ}$ 4,204,976; 27 May 1980.

Juto, N. The large scale personal monitoring service using the latest personal monitor glass badge. Proceedings of AOCR-1-Korea (2002).

Maki, D., Ube, M., Nagashima, Y., Shinozaki,W., Ueno, S., Koguchi, Y., Takeuchi, N., 2015. Development of the new glass badge. Radiat. Prot. Dosimetry, 1-9.

Miyamoto, Y., Kinoshita, K., Koyama, S., Takei, Y., Nanto, H., Yamamoto, T., Sakakura, M., Shimotsuma, Y., Miura, K., Hirao, K., 2010. Emission and excitation mechanism of radiophotoluminescence in $\mathrm{Ag}^{+}$-activated phosphate glass. Nucl. Instrum. Meth. Phys. Res. A $619,71-74$.

Pelowitz, D.B., Durkee, J.W., Elson, J.S., Fensin, M.L., James, M.R., Johns, R.C., et al., 2011. MCNPX Version 2.7.0 Extensions. Los Alamos National Laboratory, LA-UR-11-02295.

Pinto, T.N.O., Cecatti, S.G.P., Gronchi, C.C., Caldas, L.V.E., 2008. Application of the OSL technique for beta dosimetry. Radiat. Meas. 43, 332-334.

Salem, Y. O., Nourreddine, A., Nachab, A., Roy, C., Pape, A., 2015. Present state of the art of a fast neutron dosimeter incorporating RPL detectors. Journal of Nuclear Sciences. 2 , 5358.

Stabin, M. G., da Luz, L. C. Q. P., 2002. Decay data for internal dose assessment. Health Phys. 83, 471-475. See also http://www.doseinfo-radar.com. 


\section{FIGURE CAPTIONS}

Fig. 1. Dose-response curves of RPL with and without a Plexiglass filter at normal incidence to radiation from ${ }^{90} \mathrm{Sr} /{ }^{90} \mathrm{Y}$ on a $30 \times 30 \times 15 \mathrm{~cm}^{3}$ ISO water-filled phantom.

Fig. 2. Experimental energy response of an RPL detector to beta radiation at normal incidence to the detector surface. Except for ${ }^{14} \mathrm{C}$ at $0.156 \mathrm{MeV}$, all the other points were measured for ${ }^{90} \mathrm{Sr} /{ }^{90} \mathrm{Y}$ with energy sometimes degraded with a plexiglass filter.

Fig. 3. Measured RPL signal per beta disintegration as a function of the absorbed dose: (a) ${ }^{90} \mathrm{Sr} /{ }^{90} \mathrm{Y}$ source $;(\mathbf{b}){ }^{14} \mathrm{C}$ source.

Fig. 4. Difference from ${ }^{90} \mathrm{Sr} /{ }^{90} \mathrm{Y}$ on the RPL signal compared to other beta energies.

Fig. 5. Simulated directional difference from ${ }^{90} \mathrm{Sr} /{ }^{90} \mathrm{Y}$ as a function of beta energy.

\section{TABLE CAPTION}

Table 1. Maximum range of $\beta$-rays in RPL glass.

Table 2. Simulation parameters used to calculate the directional differences. 
Fig. 1

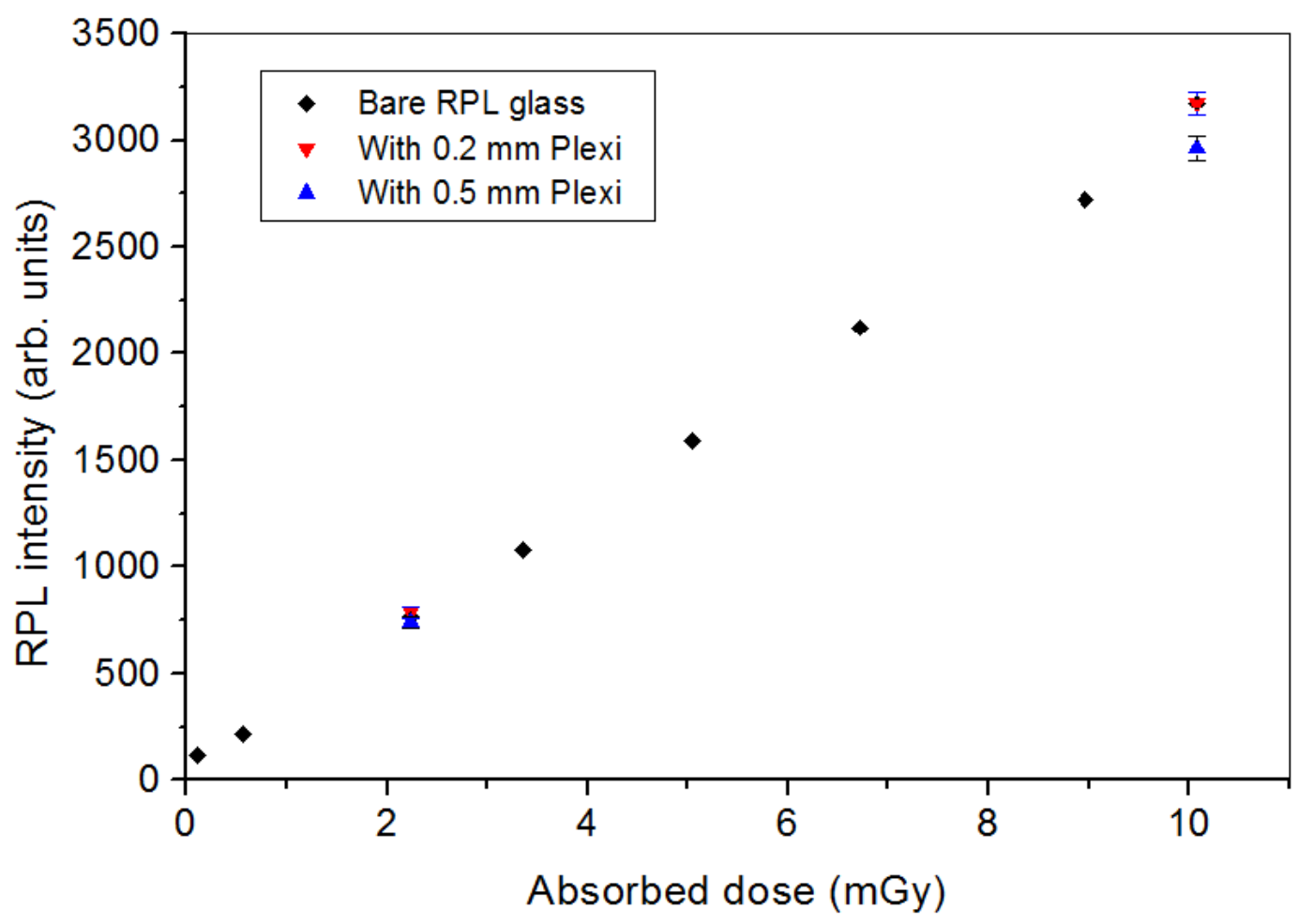

Fig. 2

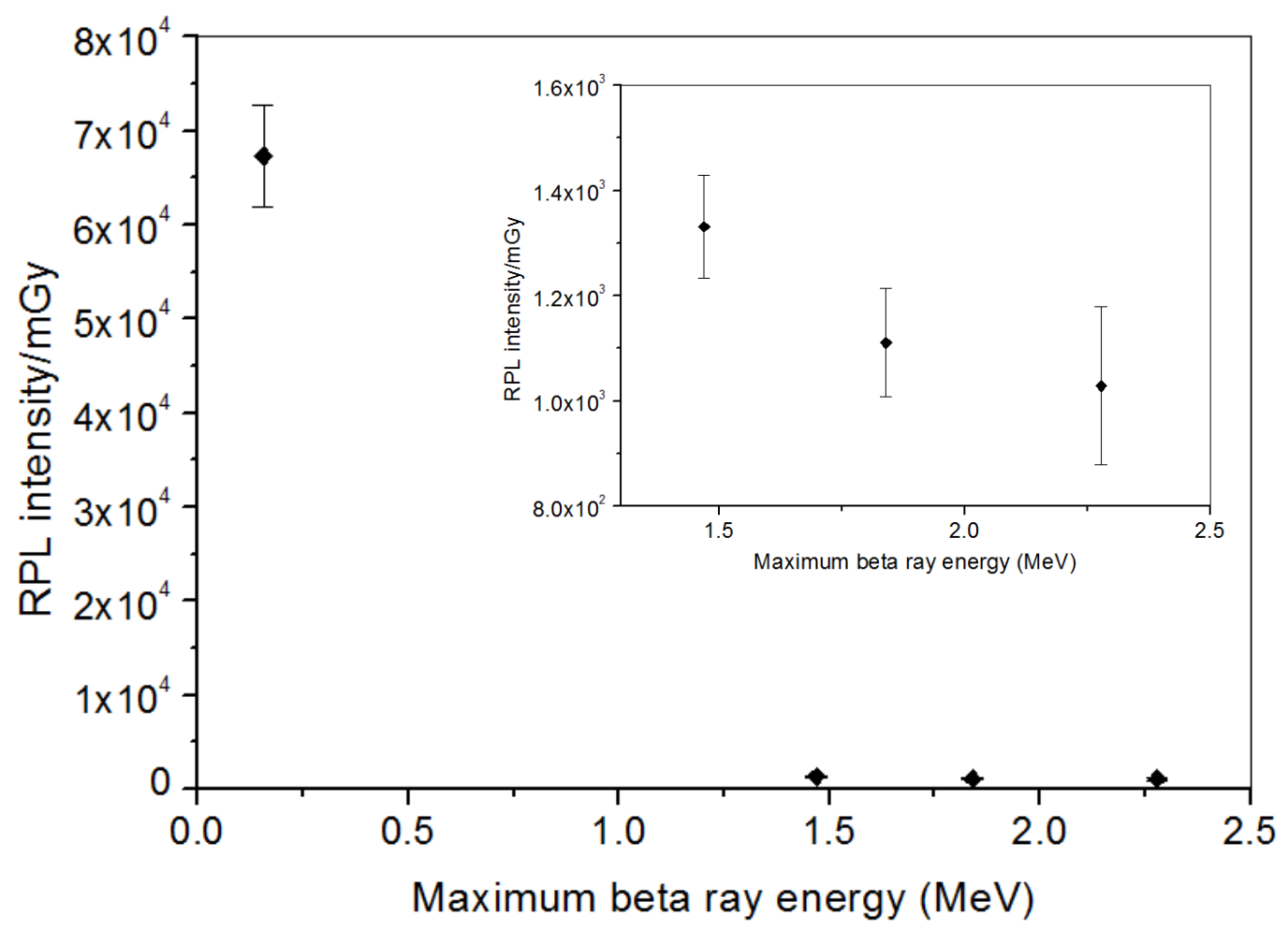


Fig. 3
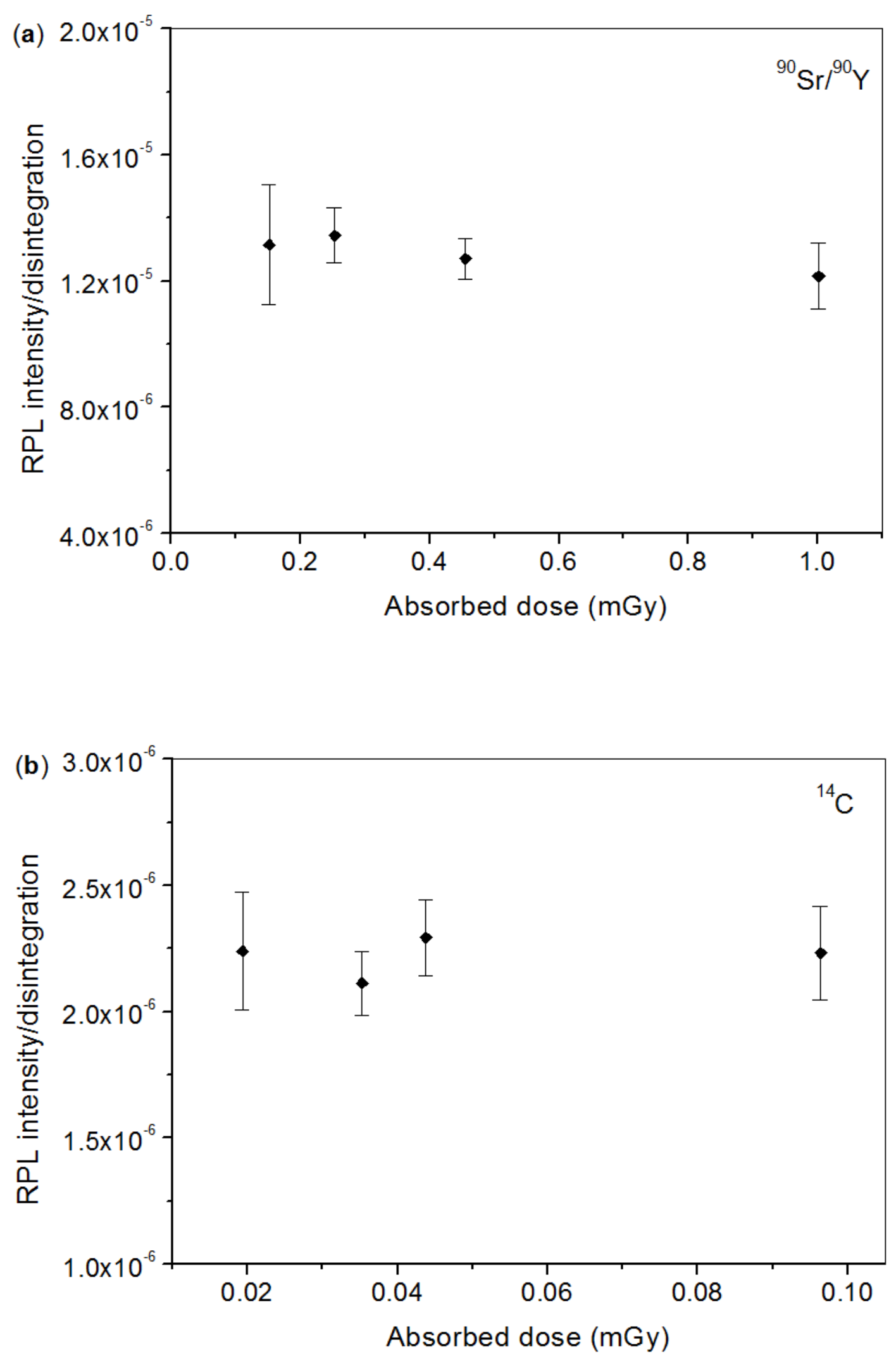
Fig. 4

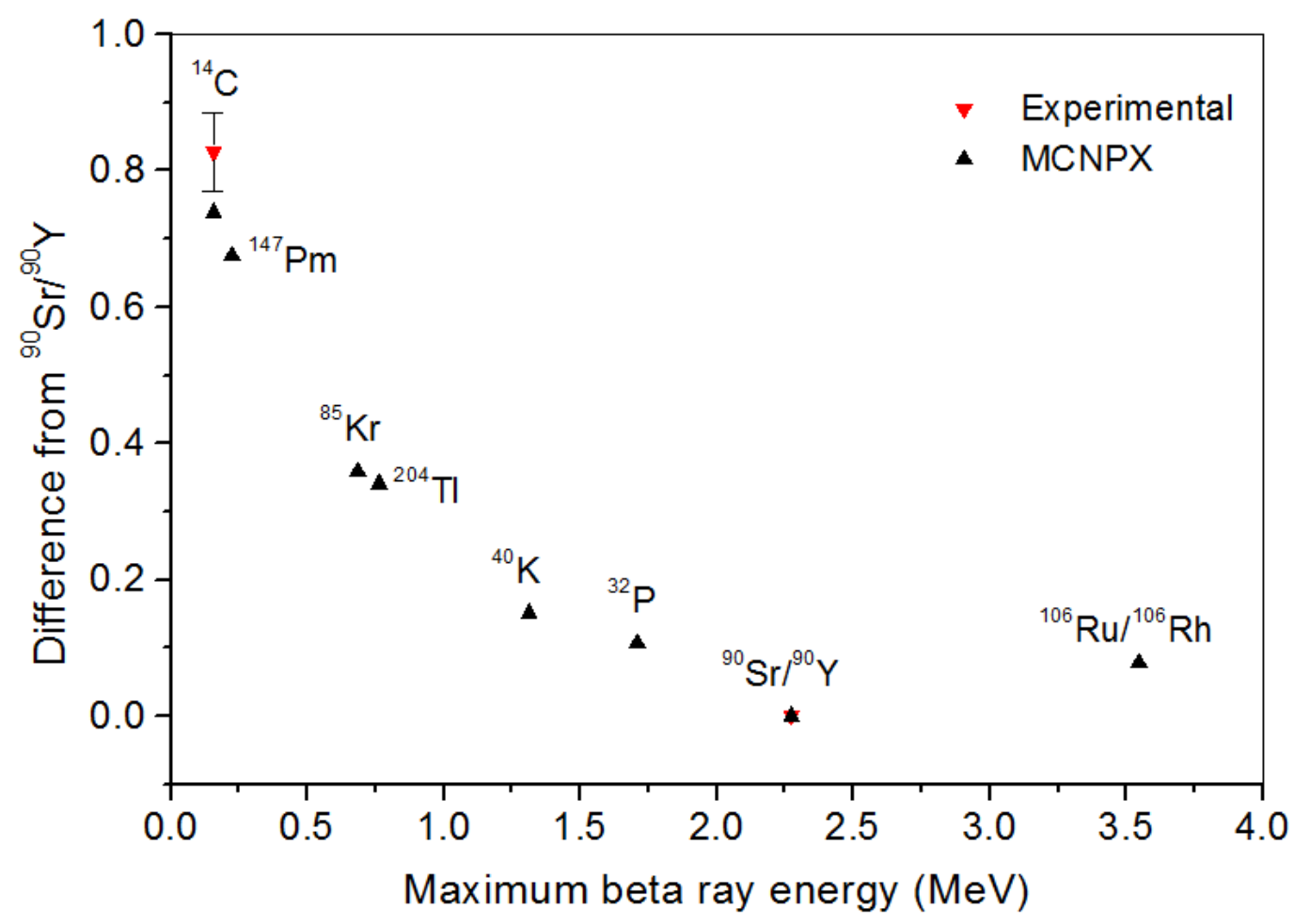

Fig. 5

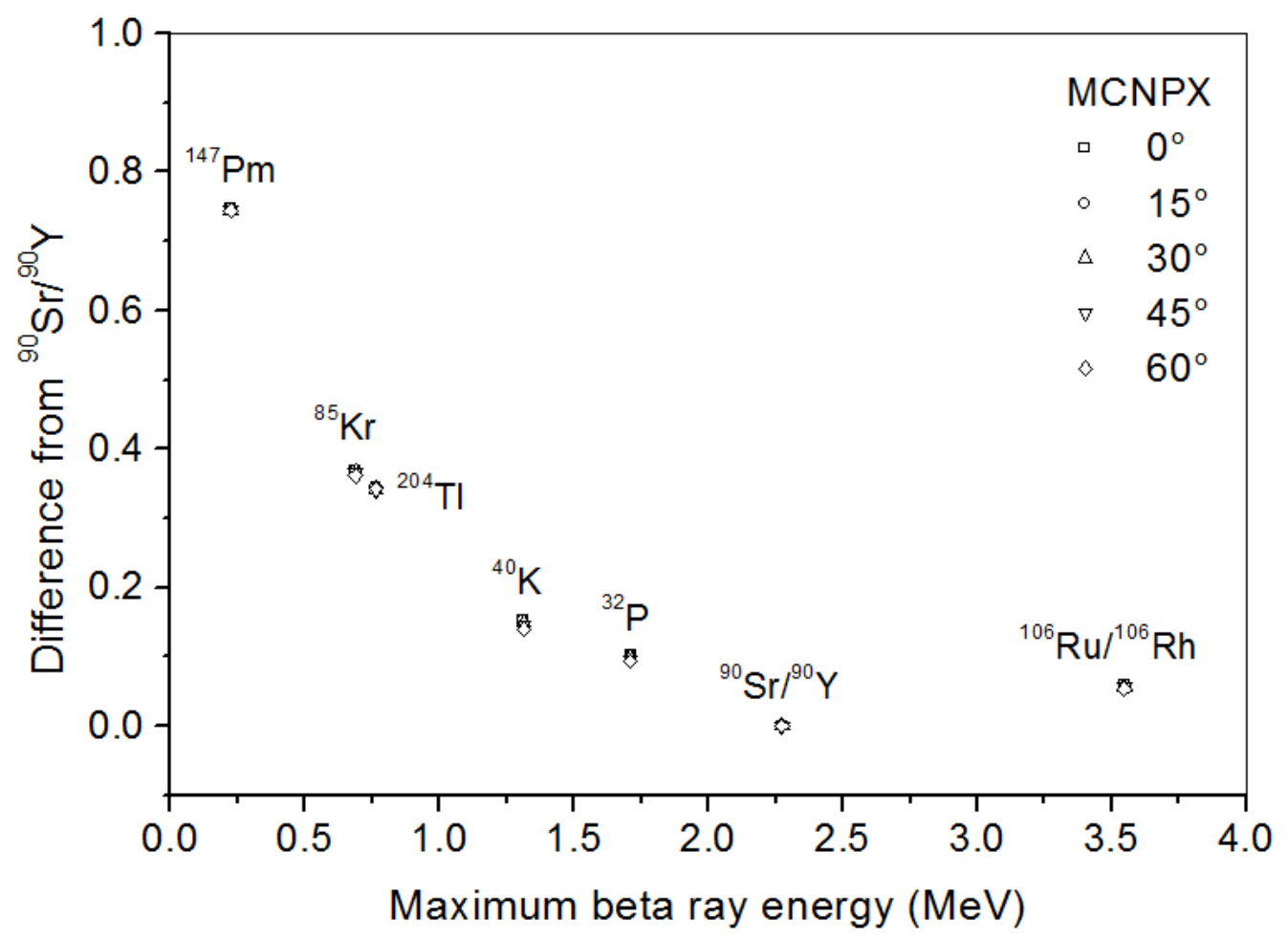


Table 1

\begin{tabular}{ccc}
\hline Source & Maximum energy $(\mathrm{MeV})$ & Range $(\mathrm{mm})$ \\
\hline${ }^{14} \mathrm{C}$ & 0.156 & 0.14 \\
${ }^{147} \mathrm{Pm}$ & 0.225 & 0.25 \\
${ }^{85} \mathrm{Kr}$ & 0.687 & 1.27 \\
${ }^{204} \mathrm{Tl}$ & 0.763 & 1.46 \\
${ }^{40} \mathrm{~K}$ & 1.311 & 2.83 \\
${ }^{32} \mathrm{P}$ & 1.710 & 3.82 \\
${ }^{90} \mathrm{Sr} /{ }^{90} \mathrm{Y}$ & 2.274 & 5.22 \\
${ }^{106} \mathrm{Ru} /{ }^{106} \mathrm{Rh}$ & 3.546 & 8.28 \\
\hline
\end{tabular}

Table 2

\begin{tabular}{ccc|c}
\hline Source & Maximum energy $(\mathrm{MeV})$ & Distance $(\mathrm{cm})$ & Angles of incidence \\
\hline${ }^{147} \mathrm{Pm}$ & 0.225 & 20 & \\
${ }^{85} \mathrm{Kr}$ & 0.687 & 30 & \\
${ }^{204} \mathrm{Tl}$ & 0.763 & 30 & \multirow{2}{*}{$0^{\circ}$ to $60^{\circ}$} \\
${ }^{40} \mathrm{~K}$ & 1.311 & 30 & \\
${ }^{32} \mathrm{P}$ & 1.710 & 30 & \\
${ }^{90} \mathrm{Sr} /{ }^{90} \mathrm{Y}$ & 2.274 & 30 & \\
${ }^{106} \mathrm{Ru} /{ }^{106} \mathrm{Rh}$ & 3.546 & 30 & \\
\hline
\end{tabular}

